\title{
Microcontainers for protection of oral vaccines, in vitro and in vivo evaluation
}

von Halling Laier, Christoffer; Gibson, Blake; Sevilla Moreno, Jorge Alberto; Rades, Thomas ; Hook, Sarah; Nielsen, Line Hagner; Boisen, Anja

Published in:

Journal of Controlled Release

Link to article, DOI:

10.1016/j.jconrel.2018.11.030

Publication date:

2019

Document Version

Peer reviewed version

Link back to DTU Orbit

Citation (APA):

von Halling Laier, C., Gibson, B., Sevilla Moreno, J. A., Rades, T., Hook, S., Nielsen, L. H., \& Boisen, A. (2019). Microcontainers for protection of oral vaccines, in vitro and in vivo evaluation. Journal of Controlled Release, 294, 91-101. https://doi.org/10.1016/j.jconrel.2018.11.030

\section{General rights}

Copyright and moral rights for the publications made accessible in the public portal are retained by the authors and/or other copyright owners and it is a condition of accessing publications that users recognise and abide by the legal requirements associated with these rights.

- Users may download and print one copy of any publication from the public portal for the purpose of private study or research.

- You may not further distribute the material or use it for any profit-making activity or commercial gain

- You may freely distribute the URL identifying the publication in the public portal 
1. Microcontainers for protection of oral

2 vaccines, in vitro and in vivo evaluation

4 Christoffer von Halling Laier ${ }^{\mathrm{a} *}$, Blake Gibson ${ }^{\mathrm{b}}$, Jorge Alberto S. Moreno ${ }^{\mathrm{a}}$, Thomas Rades ${ }^{\mathrm{c}}$,

5 Sarah Hook $^{\mathrm{b}}$, Line Hagner Nielsen ${ }^{\mathrm{a}}$, Anja Boisen ${ }^{\mathrm{a}}$

6 aDepartment of Micro- and Nanotechnology, Technical University of Denmark, Oersteds

7 Plads 345C, 2800 Kgs. Lyngby, Denmark

$8{ }^{\mathrm{b}}$ School of Pharmacy, University of Otago, Frederick street 18, Dunedin 9054, New Zealand

9 cDepartment of Pharmacy, Faculty of Health and Medical Sciences, University of

10 Copenhagen, Universitetsparken 2, 2100 Copenhagen, Denmark

\footnotetext{
* Corresponding author: Department of Micro- and Nanotechnology, Technical University of Denmark, Oersteds Plads 345C, 2800 Kgs. Lyngby, Denmark.

Phone: +45 452557 87, E-mail: cvohal@,nanotech.dtu.dk (C. von Halling Laier)
} 


\section{Abstract}

12 Oral vaccines are highly desirable due to simple logistics, mass vaccination potential and for

13 mucosal immunity. Subunit vaccines are preferred due to high safety, but are inherently 14 difficult to deliver orally, thus providing motivation for the use of advanced oral delivery 15 systems. Polymeric devices in micrometer size (microcontainers) were tested here for this 16 purpose. Microcontainers were loaded with a vaccine consisting of spray dried cubosomes 17 with OVA and Quil-A, and coated with a $\mathrm{pH}$-sensitive lid for oral delivery to $\mathrm{C} 57 \mathrm{Bl} / 6$ mice. 18 The microcontainers were explored in vitro and in vivo for their potential as oral vaccine 19 delivery system in an oral prime-boost setting and as an oral booster after a subcutaneously 20 injected prime. The $\mathrm{pH}$ of the stomach of $\mathrm{C} 57 \mathrm{Bl} / 6$ mice was measured to be $<4.7$ and it 21 ranged from $\mathrm{pH}$ 5.8-7.1 in the small intestine, where the residence time of microcontainers 22 was less than one hour. Eudragit ${ }^{\circledR}$ L100-55 was therefore chosen as lid material on the 23 microcontainers as it remained stable in vitro at $\mathrm{pH} 4.7$ and allowed release of the cubosomes 24 within 30-60 min at $\mathrm{pH} 6.6$, which simulated the mean $\mathrm{pH}$ of the distal half of the small intestine. In vitro small angle x-ray scattering showed that cubosomes dissolved in small intestinal fluid when not confined in microcontainers but when loaded into microcontainers they were released as hexosomes. However, while microcontainers could protect and release particles with OVA and Quil-A within relevant time frames in vitro, an immune response was not elicited in vivo after oral administration. Nonetheless, some effect was observed when the microcontainers were used to deliver oral boosters following a subcutaneous prime. This work indicates that oral vaccination with subunit vaccines has potential when combined with a parenteral prime and that oral delivery systems like microcontainers may be used to increase the potency of vaccines with low oral immunogenicity.

Keywords 


\section{Introduction}

Most vaccines are administered by injection, demanding trained health care personnel to administer the vaccine [1]. This can limit distribution of vaccines due to costs and logistics. The problem is exacerbated by the need for most vaccines to be injected 2-3 times over several months in order to stimulate protective immunity [2]. For example, it is recommended that the diphtheria-tetanus-pertussis vaccine is given three times, yet $14 \%$ of the world's children did not receive the third immunization in 2016 [3].

Self-administrable vaccines hold promise to greatly improve global vaccination coverage by simplifying logistics and eliminating the need for repeated health-care visits. The most attractive route for this is oral administration $[1,4]$ with, for example, vaccine provided in a capsule. Capsules for oral administration could be easily distributed for patients to selfmedicate according to a provided schedule. This additionally eliminates the need for needles, which are reported to be the main risk associated with vaccination in developing countries due to improper usage [5]. Furthermore, oral vaccination has the advantage over parenteral vaccination that it offers the possibility to achieve mucosal immunity in the gastrointestinal (GI) tract as well as at distant mucosal compartments [6-8]. Zhu et al. reported on a large intestine targeted oral vaccine against HIV which gave protection against rectal and vaginal HIV challenge [9]. This indicated that mucosal immunization may be able to give protection against some targets that have proven elusive to effective immunization through parenteral immunization.

Oral vaccines in routine clinical use are all against enteric pathogens. All are whole pathogen vaccines with most being live attenuated and only cholera vaccines being an inactivated vaccine $[4,10]$. All of them are very potent and live attenuated intestinal pathogens additionally have their own mechanisms of mucosal entry [10]. However, concerns over safety have caused an emphasis in modern vaccine research on developing subunit vaccines, which are based on purified antigenic fragments of pathogens [1,11]. This greatly improves the safety of the vaccine, but results in reduced immunogenicity, which is why adjuvants must be co-delivered with these antigens [1,4]. Subunit vaccines often use proteins or peptides as antigens, which are easily damaged and degraded by chemical and enzymatic challenges in the GI tract $[4,11]$. It is therefore important to design oral delivery systems that can protect the vaccines from these challenges. The ideal oral vaccine delivery system for subunit vaccines should protect the vaccine from degradation, limit the elimination/dilution of the vaccine in the GI tract, and facilitate uptake by M-cells in the intestine and by antigen presenting cells (APCs) to stimulate a strong immune response [10].

Microcontainers are a new approach to enable oral vaccination with subunit vaccines. Microcontainers are reservoir-based cylindrical polymeric microstructures fabricated from the polymer SU-8 with precisely controllable dimensions and an opening at one end of the cylinder. They are a versatile delivery system that can be loaded with most powder

81 formulations [12] as well as other types of formulations [13-15]. After loading, microcontainers can be sealed with a lid suitable for the application [16]. The use of $\mathrm{pH}-$ 
tract $[13,14,17]$. Microcontainers have been observed to be trapped in the intestinal mucus after intestinal perfusion in rats, thus aiding mucus penetration of the cargo [13]. They have furthermore been shown to be a promising oral drug delivery system $[13,14,18,19]$, but have never been tested as an oral vaccine delivery system. Vaccine studies are normally performed in mice which do not have the same $\mathrm{pH}$ levels in the GI tract as rats [20]. New microcontainer lids suitable for use in mice are therefore developed in this study. The $\mathrm{pH}$ in both the stomach and small intestine of $\mathrm{C} 57 \mathrm{Bl} / 6$ mice has not previously been studied, although the $\mathrm{pH}$ of the ileum and cecum of female $\mathrm{C} 57 \mathrm{~B} 1 / 6$ mice has been reported to be 6.7 and 6.4 respectively [21]. Other studies describe variable values from different strains as well as variation caused by external inputs (e.g. fasting) [20,22,23]. Since knowledge of the $\mathrm{pH}$ in the stomach and small intestine is crucial for $\mathrm{pH}$ controlled vaccine delivery, the $\mathrm{pH}$ in male C57B1/6 was measured prior to this study (supplementary material).

Quil-A is an adjuvant that is well tolerated orally [24,25], but needs to be coupled with a nanoparticle system such as cubosomes to be effective [26]. Cubosomes are composed of a highly twisted and ordered continuous lipid bilayer that forms two sets of intertwined and highly tortuous, but nonintersecting, water-channels. This gives cubosomes a large surface area making them flexible regarding the antigens and adjuvants they can carry [27]. Quil-A has previously been used for oral vaccination in a water/oil/water emulsion [28] and in ISCOMs [29-35] with some success indicating that Quil-A is suitable for oral use. We have previously reported the spray drying of cubosome precursors with ovalbumin (OVA) as model antigen and Quil-A as adjuvant. The powder formulation retained antigen integrity during storage at room temperature for at least 6 months and formed cubosomes after rehydration. The cubosomes elicited strong humoral and cellular immune responses after subcutaneous (s.c.) administration, but had no effect after oral administration indicating that a better oral delivery system was required [26]. These spray dried cubosomes are well suited for testing the efficacy of the microcontainers since they 1) have a high antigen content 2) appear to be stable during storage at room temperature and 3) are ineffective orally without a delivery system, although they are made with an adjuvant known to work mucosally. The aim of this study was to design microcontainers as oral delivery system for spray dried cubosomes, characterize the system in vitro and evaluate it in vivo in $\mathrm{C} 57 \mathrm{Bl} / 6$ mice.

\section{Materials and Methods}

\subsection{Materials}

Dimodan ${ }^{\circledR}$ MO 90/D (monoolein) was kindly donated by Danisco (Grindsted, Denmark). Dextran (from Leuconostoc spp., $40 \mathrm{kDa}$ ), ovalbumin (Grade VII, from chicken egg white) and dibutyl sebacate were purchased from Sigma-Aldrich (St. Louis, MO, USA). Quil-A was obtained from Brenntag Biosector (Frederikssund, Denmark), phosphate buffered saline (PBS) tablets were acquired from Oxoid limited (Basingstoke, England) and Eudragit ${ }^{\circledR}$ L10055 (EL100-55) was purchased from Evonik (Darmstadt, Germany). 5,6-Carboxyfluorescein diacetate succinimidyl ester (CFSE) and CellTrace ${ }^{\mathrm{TM}}$ Violet Cell Proliferation Kit (CTV) were purchased from Molecular Probes ${ }^{\circledR}$ (Eugene, OR, USA). OVA $257-264$ peptide 
126 (SIINFEKL) was acquired from Mimotopes (Clayton, Australia). PeCy7 anti-CD8,

127 propidium iodide and HRP Goat anti-mouse IgG were from BioLegend ${ }^{\circledR}$ and APC-H7 anti-

$128 \mathrm{CD} 4, \mathrm{PE}$ anti- $\mathrm{V}_{\alpha} 2$, biotin anti- $\mathrm{V}_{\beta} 5$ and APC streptavidin from BD Pharmingen ${ }^{\mathrm{TM}}$. Complete

129 mini protease inhibitor cocktail tablets were purchased from Roche Diagnostics (Mannheim

130 Germany) and Mouse Anti-OVA IgA Antibody Assay Kits from Chondrex inc. (WA, USA).

131 All other chemicals were of analytical grade and used as received. Milli-Q water (Merck

132 Millipore, Darmstadt, Germany) was used throughout the study.

6-8 weeks old male specific pathogen free C57BL/6 mice and male OT-I and OT-II mice were obtained from the HTRU, University of Otago, Dunedin, New Zealand. Mice had free access to food and water at all times. All experiments were approved by the Animal Ethics Committee at the University of Otago (AEC no. 80-16).

\subsection{Spray drying cubosomes}

140 Cubosomes were prepared as previously described [26]. Briefly, Dimodan in ethanol (5.33 $\mathrm{mg} / \mathrm{mL}$ ) was mixed 1:3.04 (v/v) with an aqueous solution of dextran, OVA and Quil-A (2.63, 0.52 and $0.035 \mathrm{mg} / \mathrm{mL}$, respectively). The mixture was spray dried on a Büchi B-290 mini spray dryer (Büchi Labortechnik AG, Flawil, Switzerland) with a pressure nozzle of $1.5 \mathrm{~mm}$ diameter. A feed rate of $4.5 \mathrm{~mL} / \mathrm{min}$ was used with atomizing airflow rate of $667 \mathrm{~L} / \mathrm{h}$, inlet temperature of $150^{\circ} \mathrm{C}$ and $100 \%$ aspirator rate. Particles without OVA were produced in the same way to be used as controls. Collected powders were stored at $86^{\circ} \mathrm{C}$ for $24 \mathrm{~h}$ and then dried at room temperature until use.

\subsection{Fabrication, loading and sealing of microcontainers}

149 Microcontainers were fabricated with the negative epoxy photoresist SU-8 by a two-step 150 photolithography process as described previously [36]. However, in this study, the design was modified to achieve a larger internal diameter while preserving the external geometry of the microcontainers to increase the loading capacity. The microcontainers were produced on top of a fluorocarbon coated silicon wafer to allow easy mechanical removal from the wafer. The wafer was then cut into 12.8 by $12.8 \mathrm{~mm}^{2}$ chips containing 25 by 25 arrays of microcontainers using a dicing saw (DISCO, Kirchheim bei München, Germany).

156 Microcontainers on chips were loaded with cubosome precursor powder using an embossing 157 method as described previously [12]. A screen-mask was used to cover the gaps between the 158 microcontainers thus filling the microcontainers without filling the space between them with 159 powder. The average powder load in the microcontainers was estimated by weighing 21 sets 160 of three individual microcontainers before and after loading.

161 After loading, the microcontainers were sealed with the $\mathrm{pH}$-sensitive polymer Eudragit ${ }^{\circledR}$ 162 L100-55 (EL100-55) through a spray coating process. Isopropanol containing $1 \%(\mathrm{v} / \mathrm{v})$ 163 EL100-55 and $5 \%$ dibutyl sebacate (w/w in relation to EL100-55) was sprayed over the chip 164 with microcontainers using an ExactaCoat spray coater (Sono Tek, Milton, NY, USA) 
equipped with an ultrasonic nozzle actuated at $120 \mathrm{kHz}$ (Accumist, Sono Tek, Milton, NY, USA). Spray coating parameters were as follows: feed flow rate $0.1 \mathrm{~mL} / \mathrm{min}$ with generator power of $2.2 \mathrm{~W}$ and nebulizing air pressure of $0.02 \mathrm{kPa}$. The chips were kept at $40^{\circ} \mathrm{C}$. The nozzle was positioned with a nozzle-to-microcontainer distance of $6.5 \mathrm{~cm}$ and moved laterally across the chip by a software controlled pattern to cover the entire chip equally. The translational speed of the nozzle was $5 \mathrm{~mm} / \mathrm{s}$ and the coating was repeated to give a total of 36 passages.

\subsection{Microcontainer characterization and qualitative release study}

Microcontainers were visualized empty, loaded with cubosome precursor powder, and sealed with EL100-55 lids using a table top scanning electron microscope (SEM) (Hitachi TM3030plus, Tokyo, Japan). Samples were placed on carbon tape on metallic holders prior to investigation and then imaged using $15 \mathrm{kV}$ acceleration voltage at $60 \mathrm{x}$ or $120 \mathrm{x}$ magnification.

The thickness of the EL100-55 lids was estimated by covering half of an SU-8 coated chip and then spray coating it as described earlier on four independent samples. The height of the produced half-lids was measured by contact profilometry (Alpha-Step IQ Stylus profilometer, KLA-Tencor Corporation, Milpitas, USA) and used as estimate of the thickness of the lids deposited on the microcontainers. Profilometry was performed at a scan speed of $20 \mu \mathrm{m} / \mathrm{s}$, using a $15.6 \mathrm{mg}$ tip force at a sampling rate of $50 \mathrm{~Hz}$.

Release of cubosomes from microcontainers sealed with EL100-55 lids was investigated qualitatively with SEM. Three full chips of microcontainers were submerged in buffer simulating the $\mathrm{pH}$ of the mouse stomach $\left(2 \mathrm{mM}\right.$ maleic acid at $\mathrm{pH} 4.7$ and $37^{\circ} \mathrm{C}$ in a water bath rotating at $120 \mathrm{rpm}$ ) for $60 \mathrm{~min}$. One chip was then removed from the buffer and imaged using SEM as described above while the two other chips were moved into buffer simulating intestinal $\mathrm{pH}\left(10 \mathrm{mM}\right.$ maleic acid at $\mathrm{pH} 6.6$ and $37^{\circ} \mathrm{C}$ in a water bath rotating at $\left.120 \mathrm{rpm}\right)$ for 30 or $60 \mathrm{~min}$. The buffer was changed every $15 \mathrm{~min}$ to simulate the sink conditions of the intestine. The microcontainers were imaged by SEM and evaluated visually for the removal of lids and powder.

Another in vitro release experiment was performed using gastric and intestinal fluids as release buffer. Here, individual microcontainers were submerged either into pooled gastric or pooled intestinal fluids (collected as described above) and placed for $30 \mathrm{~min}$ at $37^{\circ} \mathrm{C}$ in a water bath rotating at $120 \mathrm{rpm}$. Microcontainers were then recovered and imaged with SEM. The gastric and intestinal fluid was not washed off before imaging to avoid affecting the release with a washing step.

The internal structure of particles was investigated using small angle x-ray scattering (SAXS) at the Austrian SAXS/WAXS beamline at the synchrotron light source ELETTRA (Trieste,

\subsection{Small angle $x$-ray scattering of hydrated particles and particles released from microcontainers} Italy). The x-ray beam had an energy of $8 \mathrm{keV}(1.54 \AA)$ and the samples were placed 1327 $\mathrm{mm}$ from the detector. Diffraction patterns were converted to intensity vs. q-value plots to 
identify relative peak positions for determination of the space group of the dominant internal structure of the samples.

206 Powder precursors of cubosomes with OVA and Quil-A were suspended in vitro at 207 approximately $50 \mathrm{mg} / \mathrm{mL}$ into stomach or intestinal fluids at $37^{\circ} \mathrm{C}$. The structure of the 208 particles was measured at 3 minute intervals with SAXS within timeframes ranging between 2096 and 18 min depending on the sample.

210 Microcontainers were loaded with powder precursors of cubosomes with OVA and Quil-A 211 and were submerged in PBS $(9.5 \mathrm{mM}, \mathrm{pH} 7.3)$ for SAXS measurements at 3 min intervals 212 over 39 min. Powder-filled microcontainers were then sealed with EL100-55 lids and 213 submerged in PBS or in pooled intestinal fluid at $37^{\circ} \mathrm{C}$. SAXS patterns were measured every $2143 \mathrm{~min}$ for $138 \mathrm{~min}$ (PBS) and $21 \mathrm{~min}$ (intestinal fluid).

\subsection{Kinetics of microcontainer transit in the mouse GI tract}

216 Microcontainers filled with powder precursors of cubosomes with OVA and Quil-A and 217 sealed with EL100-55 lids were filled into oral capsules designed for use in mice (gelatin 218 capsules size M, Torpac ${ }^{\circledR}$, USA). The average weight of a microcontainer was estimated by 219 weighing sets of loaded and coated microcontainers. Each capsule was weighed before and after filling with microcontainers to estimate the number of microcontainers in each capsule. Mice were dosed with one capsule and sacrificed by cervical dislocation after 60 or $90 \mathrm{~min}$ followed by collection of their stomach, small intestine, cecum and colon. The small intestine was divided into a proximal and a distal segment. Segments were examined with optical microscopy (Olympus IX53 inverted microscope with 4x bright-field optics) to count the number of microcontainers present in each segment. For each mouse, the recovered numbers of microcontainers in each segment were normalized to the total number of microcontainers recovered from all segments. Three mice were used for each time point.

\subsection{In vivo immunological investigation of microcontainers loaded with cubosomes as} oral vaccines

230 Two vaccine studies were performed. In both studies, $200 \mu \mathrm{L}$ PBS with $2 \times 10^{6}$ naïve OT-I and OT-II lymphocytes (which have T cell receptors for CD8 and CD4 epitopes from OVA [37]) were injected intravenously (i.v.) into the tail vein 1-3 days prior to the first vaccination.

The first study evaluated microcontainers as an oral vaccine. Six groups of five mice were given three oral immunizations as described in Figure 1a. Further details of the vaccination regime are included in Table S1. As a positive control, one group of mice was vaccinated twice s.c. with cubosomes containing $10 \mu \mathrm{g}$ OVA and $0.67 \mu \mathrm{g}$ Quil-A, while the oral vaccines contained $100 \mu \mathrm{g}$ OVA and $6.7 \mu \mathrm{g}$ Quil-A.

238 The second study investigated microcontainers as an oral boost. Five groups of six mice

239 received an s.c. prime followed by two boosts orally or s.c. as described in Figure 1b. Further 240 details of the vaccination regime are included in Table S2. Doses were $10 \mu \mathrm{g}$ OVA and 0.67 $241 \mu \mathrm{g}$ Quil-A. 
The s.c. vaccines were injected into the flank of the mice, whilst liquid oral vaccines were administered by gavage using a soft gavage needle (category $\# 7202 \mathrm{~K}$, Fuchigami, Kyoto, Japan) and oral capsules were dispensed into the back of the mouth of the mouse using a dosing syringe. Four days after the last vaccination, mice were injected i.v. with $4 \times 10^{6}$ C57Bl/ $/ 6$ lymphocytes pulsed with $10 \mu \mathrm{g} / \mathrm{ml}$ SIINFEKL and labelled with CFSE together with $4 \times 10^{6}$ unpulsed lymphocytes stained with CTV. On day 33, mice were moved to fresh cages for collection of fresh fecal pellets from the cage floors on day 34 . Fecal pellets were stored at $-20^{\circ} \mathrm{C}$ until analysis. Mice were sacrificed on day 34 and blood, spleens and lymph nodes (mesenteric and inguinal lymph nodes from mice vaccinated orally or s.c., respectively) were collected.

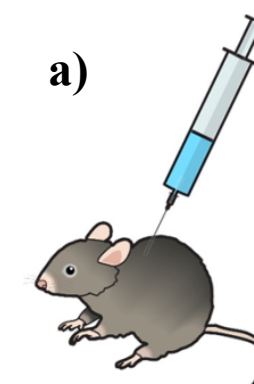

\section{s.c. immunization with:}

6. cubosomes + OVA + Quil-A
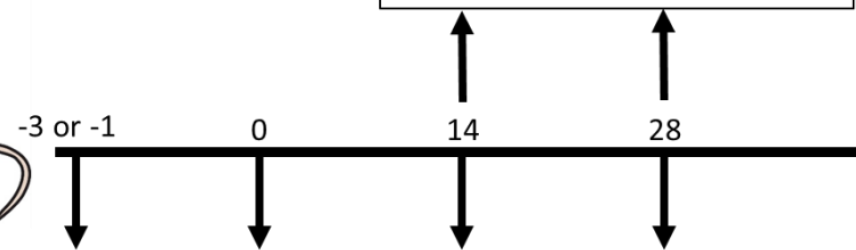

OT-I/OT-I

Oral immunizations with:

adoptive 1. Microcontainers + cubosomes + OVA + Quil-A

transfer 2. Microcontainers + OVA + Quil-A

3. Cubosomes + OVA + Quil-A

4. OVA + Quil-A

5. Microcontainers + cubosomes + Quil-A
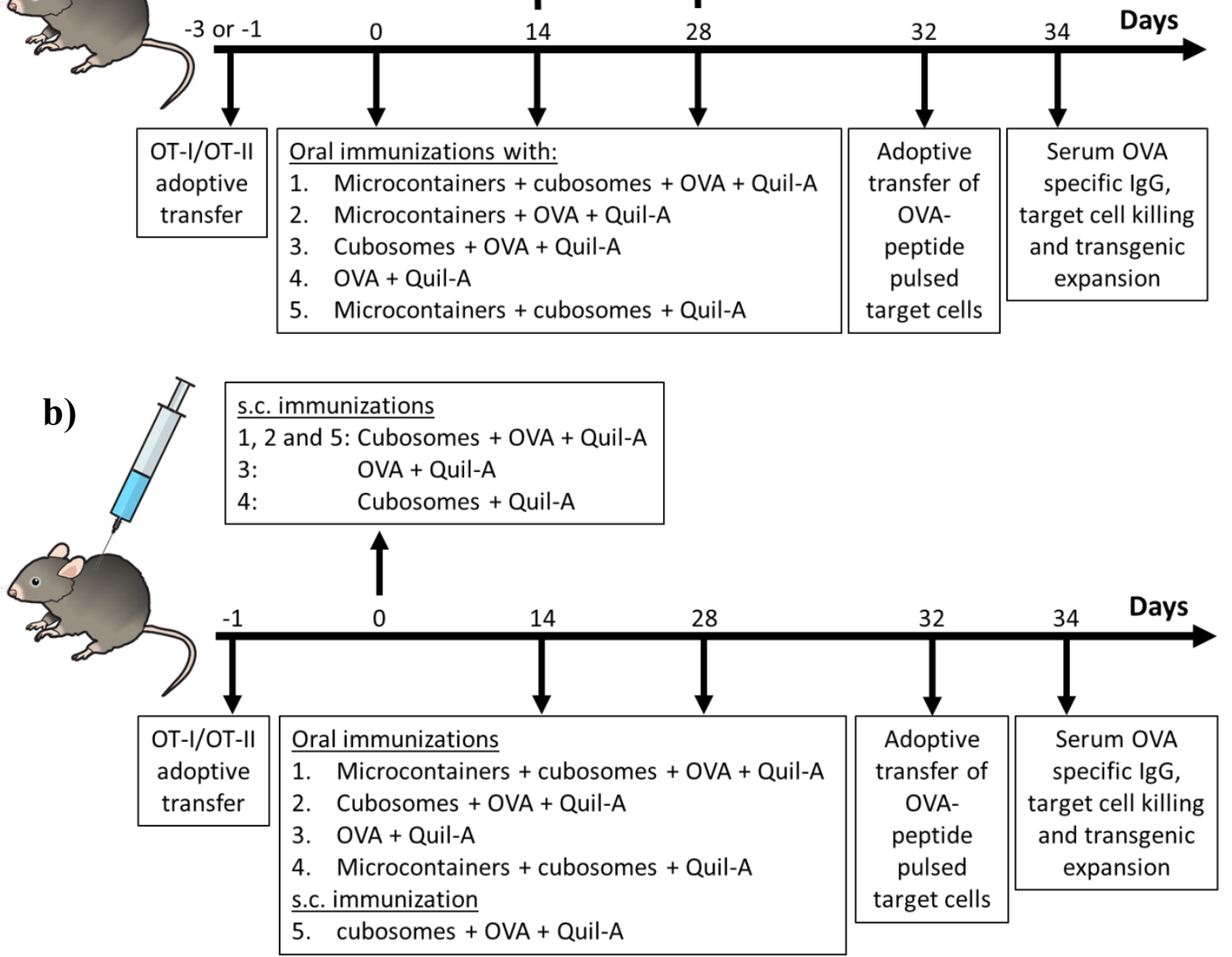

5. cubosomes + OVA + Quil-A

254 Figure 1. Schematics of the in vivo studies investigating (a) oral prime and boost or (b) s.c. prime followed by oral boosts. Positive control groups received s.c. prime and boost in both studies. Numbering of groups correspond with those of Tables S1 and S2. 
259 Spleens and lymph nodes from individual mice were processed into single cell suspensions essentially as described previously [38]. Aliquots of cells were stained with anti-CD8, anti$\mathrm{CD} 4$, anti- $\mathrm{V}_{\alpha} 2$ and anti- $\mathrm{V}_{\beta} 5$ antibodies and the live/dead stain propidium iodide. Data was acquired on a BD FACSCanto ${ }^{\mathrm{TM}}$ II (BD Biosciences) and analyzed using FlowJo version 10.3 (Tree Star, Inc.) with the gating strategy shown in Figure S1. Antigen specific killing of peptide pulsed target cells was evaluated as described previously [26].

\subsection{Measurement of OVA-specific serum IgG and OVA-specific fecal and serum IgA}

Sera were separated from whole blood and OVA-specific serum IgG was measured by ELISA as previously described [26]. Briefly, wells were coated with OVA and then blocked with $2 \% \mathrm{w} / \mathrm{v}$ BSA in PBS (9.5 mM, pH 7.3). Sera were diluted 1:100, serially diluted across well plates (high-binding 96 well plate, Corning inc. Corning, NY, USA) and incubated for 2 h. $225 \mathrm{ng} / \mathrm{mL}$ HRP Goat anti-mouse IgG was used as detection antibody and color was developed using a substrate reagent pack (R\&D SYSTEMS ${ }^{\circledR}, \mathrm{MN}$, USA). Color development was stopped with $2 \mathrm{M} \mathrm{H}_{2} \mathrm{SO}_{4}$ and absorbance at $450 \mathrm{~nm}$ was read using a Polarstar Omega Microplate Reader (BMG Labtech, Ortenberg, Germany)

For IgA measurement, fecal pellets were powdered with morter and pestle and IgA was extracted from the solids by mixing at $150 \mathrm{mg} / \mathrm{mL}$ in PBS $(9.5 \mathrm{mM}, \mathrm{pH} 7.3)$ containing protease inhibitors used according to the manufacturer's protocol. The extraction was run for $45 \mathrm{~min}$ and agitated repeatedly by aspirating and ejecting through a $1 \mathrm{~mL}$ syringe. Solids were separated from liquid by centrifugation for $10 \mathrm{~min}$ at 2,000 $\mathrm{G}$ and OVA-specific IgA in the supernatants was measured using an ELISA kit according to manufacturer's instructions. OVA-specific IgA from pooled undiluted sera was measured using the same protocol.

\subsection{Statistics}

282 Data are presented as mean \pm standard deviation (SD), except the $\mathrm{pH}$ measurements which are presented as median with quartiles and extrema together with the mean. Statistical analysis was performed by one-way ANOVA and Tukey's multiple comparisons test using Prism 7 (GraphPad, San Diego, USA).

\section{Results and discussion}

\subsection{Cubosomes retain their structure in stomach fluid but are degraded in intestinal fluid}

A dry flowable powder of cubosome precursors with OVA and Quil-A was prepared by spray drying and formed Pn3m cubosomes when dispersed in PBS as previously described [26]. Following oral administration, however, the gastric and intestinal fluids may affect the structure of the nanoparticles in vivo and this has not previously been investigated. To investigate if cubosomes form after oral administration to mice, the powder was mixed into stomach and intestinal fluids from mice in vitro. Cubosomes formed immediately in stomach 
either intestinal segment, SAXS patterns without peaks (characteristic of vesicles) were obtained (Figure 2). This indicates that cubosomes are stable for at least $18 \mathrm{~min}$ in stomach fluid, but quickly lose their cubic structure to form vesicles in intestinal fluid.

299 Since cubosomes are lipid-based particles, they may be expected to be emulsified into vesicles by bile salts. This is consistent with our results as bile salts are present in large amounts in the intestine while no or only small amounts of bile salts are reported to be present in the stomach [39]. For oral administration to mice, it was therefore important that the microcontainers are able to not only protect the antigen from chemical and enzymatic degradation in the stomach, but also to protect the cubosomes from emulsification by bile salts in the intestine. Because microcontainers are known to be trapped in the mucus close to the intestinal wall [13], emulsification would be reduced by the release of cubosomes near the epithelium. As will be shown below, the chemistry of the lid may also provide protection of the particles even after release.

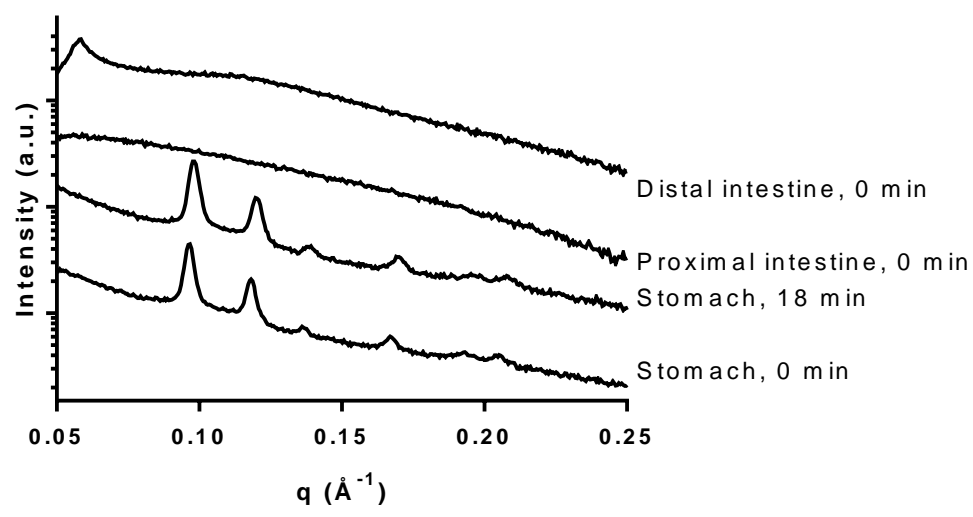

311 Figure 2. q vs. intensity patterns obtained from SAXS measurements of cubosomes with 312 OVA and Quil-A mixed in vitro with fluids from segments of the GI tract of mice at $37^{\circ} \mathrm{C}$.

313 Measurements were performed at 0 and $18 \mathrm{~min}$ after mixing cubosomes into stomach fluid 314 and 0 min after mixing cubosomes into fluid from the proximal or distal half of the small 315 intestine.

318 Microcontainers were fabricated with an outer diameter of $326.3 \pm 1.0 \mu \mathrm{m}$ and height of $319255.4 \pm 6.0 \mu \mathrm{m}$, and with an inner diameter of $231.5 \pm 0.9 \mu \mathrm{m}$ and height of $216.8 \pm 6.4 \mu \mathrm{m}$, 320 giving a reservoir volume of $9.1 \pm 0.3 \mathrm{~nL}(\mathrm{n}=4$, mean $\pm \mathrm{SD})$. Microcontainers were loaded 321 with $6.6 \pm 4.6 \mu \mathrm{g} /$ microcontainer of powder and then sealed with EL100-55 lids. The average 322 thickness of the lid coating was measured by contact profilometry to be $29.7 \pm 3.5 \mu \mathrm{m}$ with a surface roughness (SD of the thickness of the individual chip) $\leq 1.2 \mu \mathrm{m}$. 
326 The $\mathrm{pH}$-activated release of cubosomes from coated microcontainers was tested in vitro. For simulation of gastric $\mathrm{pH}$, the highest $\mathrm{pH}$ that may be expected in the stomach was chosen to ensure that biological variance would not cause unexpected lid disintegration in the subsequent in vivo evaluation. Microcontainers (Figure 3a) were therefore submerged in buffer at $\mathrm{pH} 4.7$ and $37^{\circ} \mathrm{C}$ to simulate stomach $\mathrm{pH}$ of C57Bl/6 mice (Supplementary material). After 60 min, the EL100-55 lids were completely intact (Figure 3b) and the microcontainers were moved to buffer at $\mathrm{pH} 6.6$ to simulate the $\mathrm{pH}$ of the distal segment of the small intestine (Supplementary material). Here, the lids dissolved and most of the cubosomes were released within 30 min (Figure 3c), although a small amount was still left at the top of most microcontainers (but not deep into the reservoir). After $60 \mathrm{~min}$, most microcontainers were empty (Figure 3d).

337 The experiment was repeated in vitro using fluids from the stomach, and the proximal- and distal segments of the small intestines of mice. Once again, lids were intact after $30 \mathrm{~min}$ in the stomach, but dissolved within $30 \mathrm{~min}$ in the proximal segment of the intestine (Figure

340 S2). The microcontainers generally appeared empty after $30 \mathrm{~min}$ in fluid from either segment of the intestine but the degree of emptying was difficult to evaluate due to the presence of sticky solids in the intestinal fluids (Figure S2). Lids made from Eudragit L100-55 thus appear to have the same function in mice as we have previously observed for rats with lids made from Eudragit L100 [13].

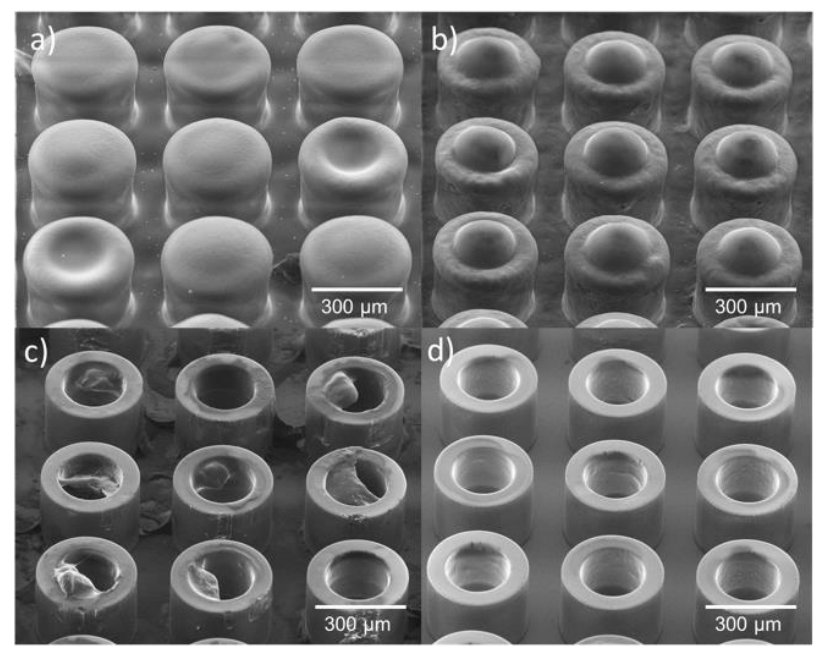

346 Figure 3. SEM images showing dry microcontainers on a chip after loading with cubosomes 347 and coating with EL100-55 (a). Microcontainers were soaked for $60 \mathrm{~min}$ in $2 \mathrm{mM}$ maleic acid 348 at $\mathrm{pH} 4.7$ simulating the $\mathrm{pH}$ of the mouse stomach (b) and then in $10 \mathrm{mM}$ maleic acid at $\mathrm{pH}$ 3496.6 simulating $\mathrm{pH}$ of the mouse intestine for $30 \mathrm{~min}(\mathrm{c})$ and $60 \mathrm{~min}(\mathrm{~d})$. 
352 The entrapment of monoolein-based cubosome precursors in microcontainers sealed with

353 Eudragit ${ }^{\circledR}$ S100 lids has previously been reported to result in hexosomes being formed after

354 release of the precursors into water [17]. However, it was not tested whether it was the microcontainers or the lids that cause the change in particle morphology. Here, the effect on particle morphology of sealing the microcontainers with EL100-55 lids was investigated in addition to the effect of microcontainers on their own. Powder precursors loaded into microcontainers and released into PBS were investigated with SAXS. Release of cubosome precursors from microcontainers without lids resulted in Bragg peaks at relative positions of $\sqrt{2}: \sqrt{3}: \sqrt{4}: \sqrt{6}: \sqrt{8}: \sqrt{9}$ (Figure $4 a$ ) characteristic of Pn3m cubic phase $[40,41]$ similar to those from cubosomes without microcontainers [26]. The peaks were evident after $6 \mathrm{~min}$ and persisted thereafter (shown at $30 \mathrm{~min}$, the measurement was stopped after $39 \mathrm{~min}$ ). This indicates that microcontainers do not affect particle morphology, as was expected since the cubosomes only form after rehydration [26] and thus after release.

Particles released from microcontainers with EL100-55 lids resulted in Bragg peaks at relative positions of $\sqrt{1}: \sqrt{3}: \sqrt{4}$ (Figure 4a) characteristic of hexagonal phase [40]. SAXS patterns from the hexosomes became increasingly sharper even $60 \mathrm{~min}$ after submersion in PBS. Since microcontainers do not affect particle morphology, this indicates that after dissolution of the lids, the components of the lids interact with the lipid changing the particle morphology from cubosomes to hexosomes.

371 In the pure monoolein/water phase diagram, the hexagonal phase exists only at temperatures above $80^{\circ} \mathrm{C}$ [42]. However, the addition of other amphiphiles with a higher hydrophobicity than monoolein, or lipophilic additives, can transform the cubic phase to a hexagonal phase $[42,43]$. At pH 6.6, EL100-55 will be mostly deprotonated and thus have a hydrophilic structure that allows its dissolution in water. The addition of EL100-55 at pH 6.6 is therefore not an obvious driving factor for the observed phase change. The only other component of the lid is the dibutyl sebacate used as plasticizer for the EL100-55 lids. Dibutyl sebacate was chosen for its hydrophobic nature, which provides more water tight lids than when using a hydrophilic alternative [44]. It is therefore likely to become incorporated into the monoolein

380 bilayers where it might affect the packing of the lipids increasing curvature and consequently driving the phase change from the inverse cubic to the inverse hexagonal structure $[45,46]$. However, no plasticizer was used in the study by Nielsen et al., where a mixture of cubosomes and hexosomes were released from Eudragit ${ }^{\circledR}$ S100 coated microcontainers [17]. Since the two Eudragit types are copolymers composed of the same monomers at different ratios, it is likely that both EL100-55 and dibutyl sebacate have influence on the observed complete phase change observed in this study. The explanation might be that their incorporation reduces the packing frustration of the lipid bilayer inherent to the hexagonal structure [46].

389 Interestingly, hexosomes were also formed when the precursor powder was released from 390 microcontainers with lids into intestinal fluid from mice (Figure 4b). They take some time to 391 form the crystal structure though as evident from the time-dependent change of diffraction 392 pattern from a soft hump to clear peaks. Since release of cubosomes from the microcontainers 
is expected to happen in the mucus, it is likely that hexosomes with OVA and Quil-A will form in vivo in the mucus in close proximity to the intestinal wall, where the antigensampling M-cells and dendritic cells are present. Any type of particle generally facilitates the recognition and uptake of antigen by antigen presenting cells [47]. This morphology change is therefore likely not of substantial importance to the stimulation of an immune response. However, release of actives from the bulk hexagonal phase is generally slower than from the bulk cubic phase [48]. It could therefore be speculated that hexosomes retain the antigen better than cubosomes, and thereby might stimulate a better immune response [11].

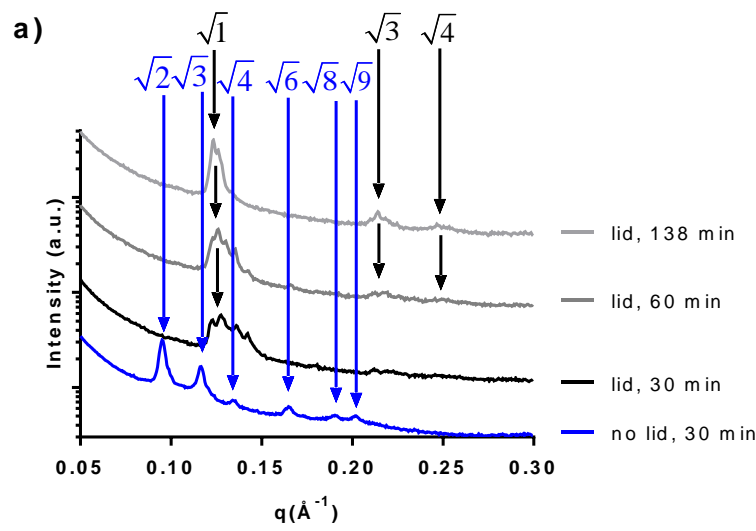

b)

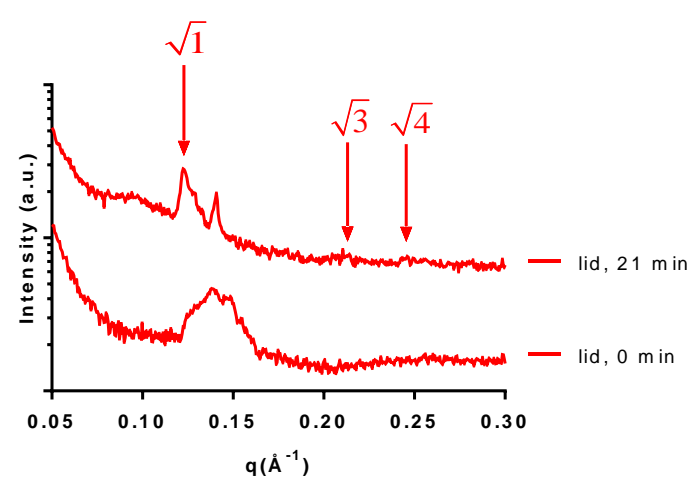

401

402 Figure 4. q vs. intensity patterns obtained from SAXS measurements of particles with OVA and Quil-A released from microcontainers at (a) $37^{\circ} \mathrm{C}$ in PBS and (b) in mouse intestinal fluid. SAXS patterns shown in (a) are from particles released from microcontainers without lid after 30 min and with lid after 30,60 and $138 \mathrm{~min}$. SAXS patterns shown in (b) are from particles released from microcontainers with lid just after submersion in mouse intestinal fluid and after $21 \mathrm{~min}$.

\subsection{Kinetics of microcontainer transit in the mouse GI tract}

409 The transit time of microcontainers or similarly sized particles through the GI tract of mice 410 has never been evaluated, but is important for interpretation of in vitro studies of vaccine 411 release from the microcontainers. To investigate whether the microcontainers stay long 412 enough in the intestine to allow release of the vaccine before the microcontainers are expelled 413 with the feces, the transit time through the GI tract was evaluated. Mice were administered 414 one capsule loaded with microcontainers and were sacrificed after 60 or $90 \mathrm{~min}$.

415 Microcontainers were quantified by microscopy and $86 \pm 11 \%$ of the estimated number of 416 administered microcontainers were found in each mouse (Figure 5). The microcontainers 417 were generally spread widely within each mouse indicating a large variability in how fast 418 individual microcontainers move through the GI tract. However, after 60 minutes more than $41960 \%$ of the microcontainers had passed the stomach, and $58 \%$ of the microcontainers were 420 distributed along the small intestine. After $90 \mathrm{~min}$, the majority of microcontainers recovered were present in the cecum and colon. The time available for release in the small intestine is therefore short and some of the vaccine might be released in the large intestine. Both the 
cecum and the colon contain lymphoid tissue [20] and are good mucosal vaccine targets to obtain immunity at rectal and vaginal mucus surfaces [9].

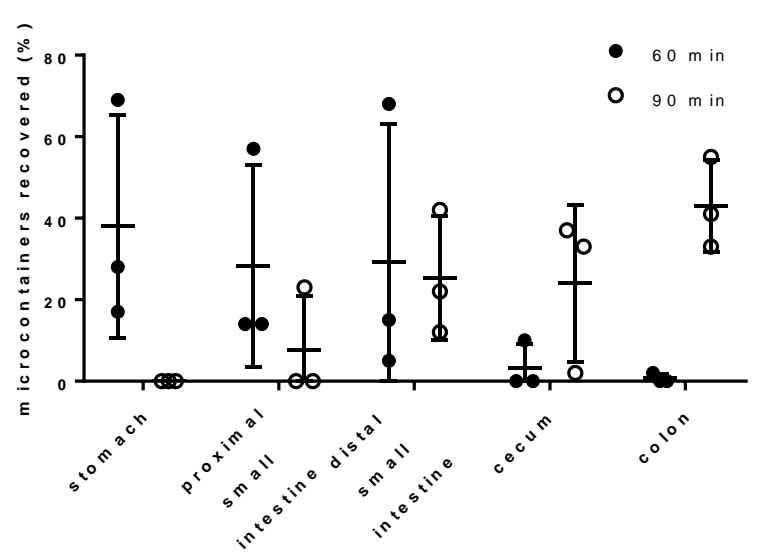

426

427 Figure 5. Relative numbers of recovered microcontainers found in the stomach, proximal428 and distal half of the small intestine, cecum and colon in mice killed 60 or 90 min after oral 429 administration. Error bars represent mean $\pm \mathrm{SD}(\mathrm{n}=3)$.

430

3.6. Oral cubosomes elicit a weak humoral immune response but no response when delivered in microcontainers

433 Microcontainers appear to have promise as an oral delivery system and were therefore 434 evaluated in vivo. Microcontainers were administered in capsules because their $\mathrm{pH}$-sensitive 435 lids would dissolve in buffer at neutral $\mathrm{pH}$. OVA-specific serum IgG titers were measured by 436 ELISA to evaluate the humoral immune response to the vaccines. A strong anti-OVA IgG 437 response was seen after s.c. administration as previously reported [26]. Oral cubosomes 438 resulted in slightly increased IgG response in one experiment (Figure 6), but not in the 439 replicate of the experiment (not shown). OVA and Quil-A delivered in capsules or in 440 microcontainers (in capsules) with or without cubosomes had no effect. 


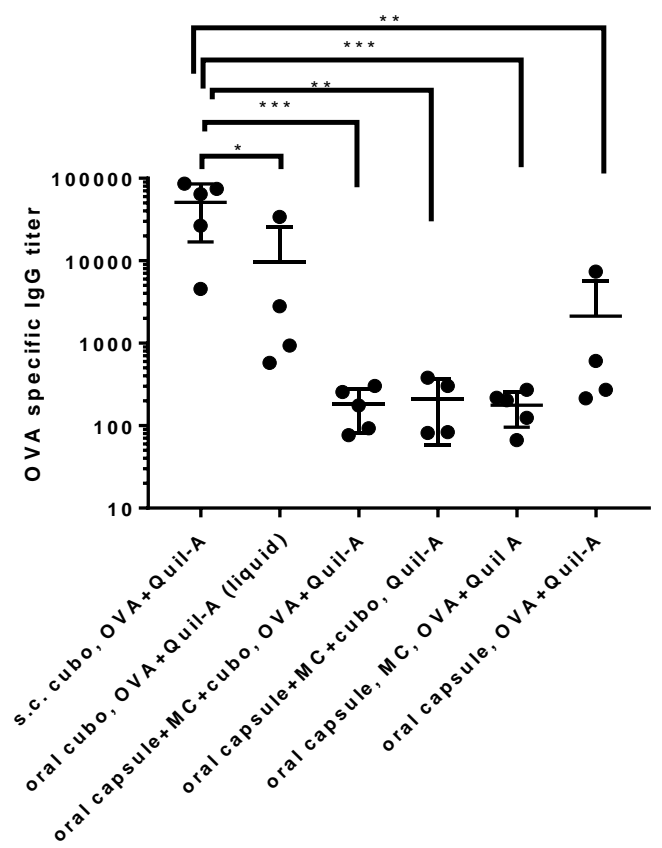

442 Figure 6. OVA-specific serum IgG antibody titers. Mice were given vaccines three times 443 orally or two times s.c. as indicated with 14 days between each vaccination. Data shown are 444 from individual mice plus the average and SD (data is from 1 of 2 independent experiments, $445 \mathrm{n}=4-5$ mice/experiment). $* \mathrm{p}<0.5, * * \mathrm{p}<0.1, * * * \mathrm{p}<0.001$, cubo $=$ cubosomes, $\mathrm{MC}=$ 446 microcontainers.

448 Fecal and serum OVA-specific IgA titers were measured by ELISA to evaluate the mucosal 449 immune response. Low and inconsistent levels of IgA were seen in pooled fecal and serum 450 samples from oral cubosomes (Figure 7). Mice treated orally with cubosomes in 451 microcontainers had low levels of $\operatorname{IgA}$ in serum in one experiment. 

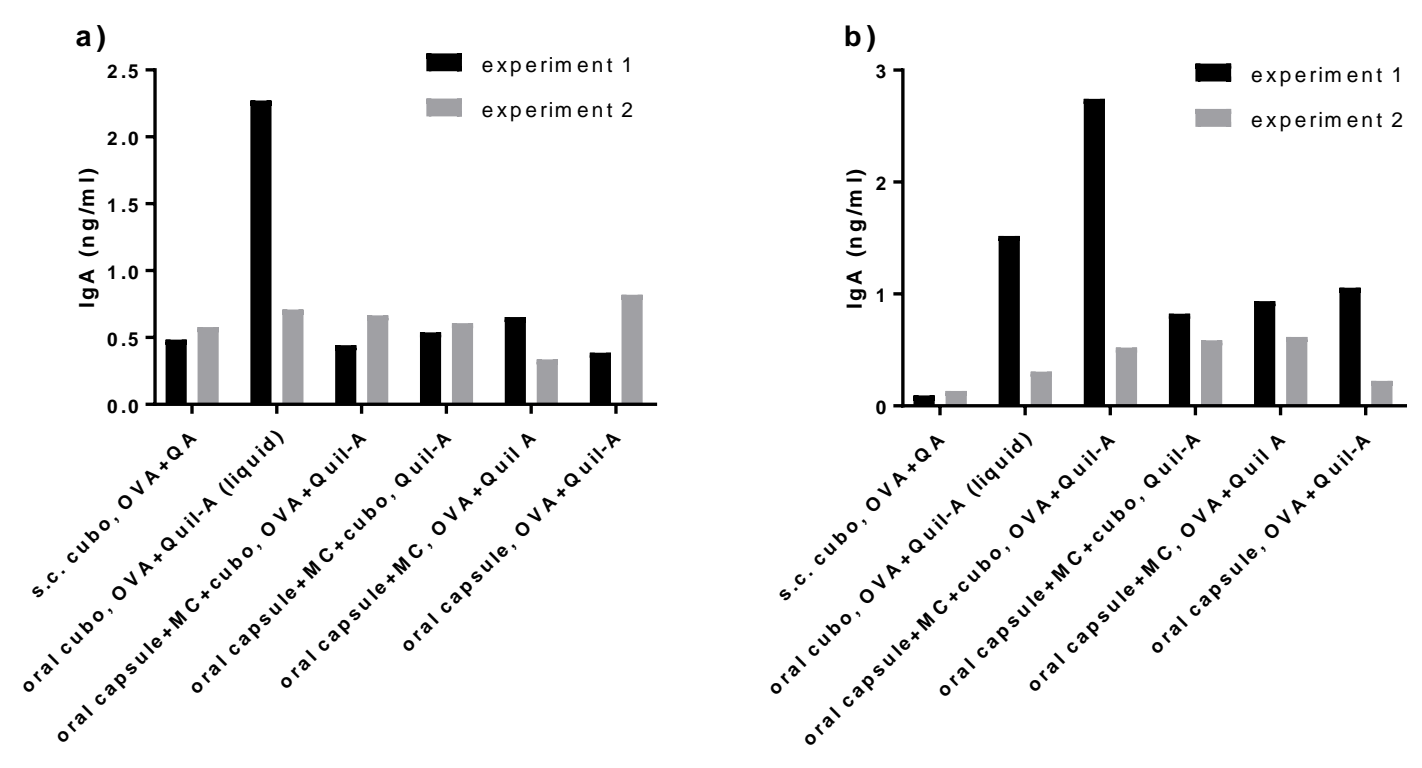

454 Figure 7. OVA-specific IgA from (a) fecal samples collected at the time of sacrifice and (b) serum samples. Mice were given vaccines three times orally or two times s.c. as indicated with 14 days between each vaccination. Data are from pooled mice with 4-5 mice/group. cubo $=$ cubosomes, $\mathrm{MC}=$ microcontainers .

\subsection{Oral cubosomes inconsistently elicit a cellular immune response but no response} when delivered in microcontainers

461 Expansion of OVA-specific transgenic cells was used to evaluate the cellular immune response to the vaccines (Figure 8) along with an in vivo cytotoxicity assay to measure cytotoxic T cell responses (Figure 9). For the in vivo cytotoxicity assay, killing of OVApeptide labelled lymphocytes injected i.v. two days before sacrifice was measured.

Subcutaneous injection of cubosomes elicited strong OVA-specific CD8 $8^{+}$expansion in lymph nodes and spleens (Figure 8a and c) as well as target cell killing (Figure 9) as observed previously [26]. Oral cubosomes with OVA and Quil-A were able to elicit a strong CD8 ${ }^{+}$ response in two mice, but had no effect in the remaining three mice (Figure 8a and c). All other oral treatments had no effect. The $\mathrm{CD} 4^{+}$responses were generally weak (Figure $8 \mathrm{~b}$ and d). A slight $\mathrm{CD}^{+}$response was observed in the same mice treated with oral cubosomes with OVA and Quil-A that also expressed strong $\mathrm{CD} 8^{+}$responses and in some of the mice treated with cubosomes s.c. Oral cubosomes caused variable target cell killing, but this was not comparable to the effect of s.c. cubosomes (Figure 9). All other oral groups did not stimulate target cell killing.

We have previously observed that these cubosomes do not work orally when administered in powder form in a capsule [26]. In this study, the powder form of the cubosomes in microcontainers was also ineffective, whereas cubosomes that had been rehydrated prior to gavage had a small effect. It therefore seems that when this vaccine is administered in powder 
479 form, it is not suitable for oral delivery, even if using an oral delivery system. However, both 480 cubosomes and microcontainers have the potential to be further developed and

a)

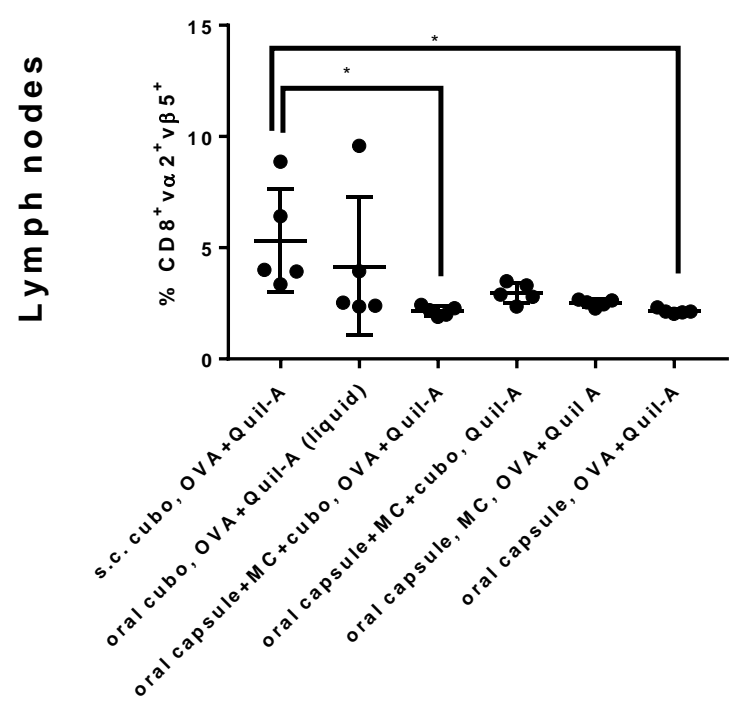

c)

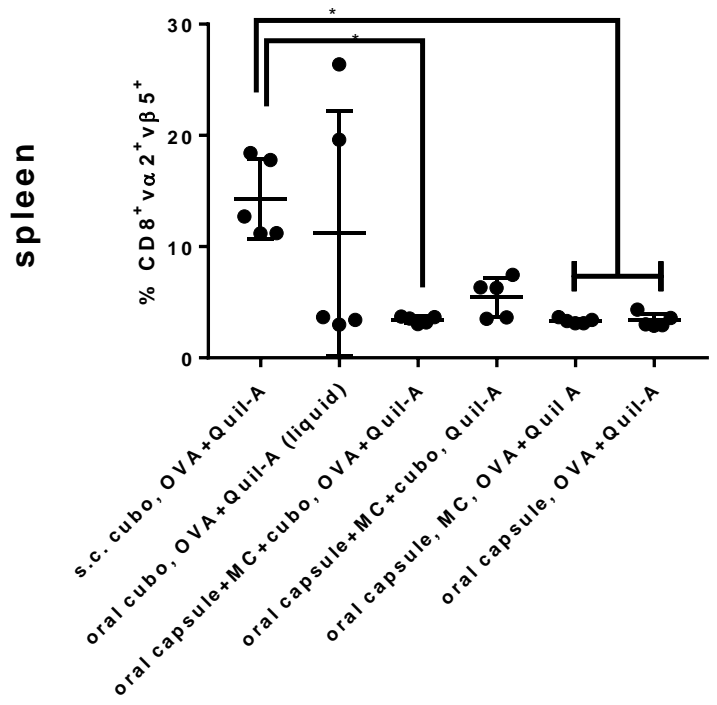

481 micro

482 contai

483 ners

b)

CD $4^{+}$

484 can be

485 couple

$486 \quad d$ to

487 differe

488 nt

489 vaccin

490 e

formu

lations

warra

nting

furthe

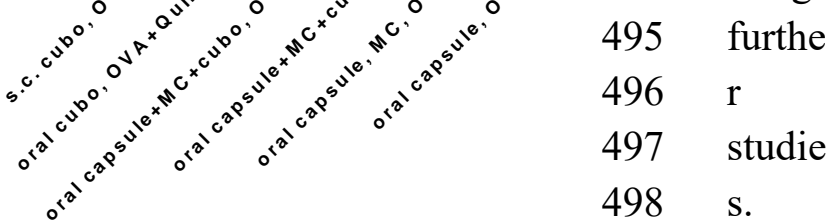

d)

499 Figur

500 e 8. In

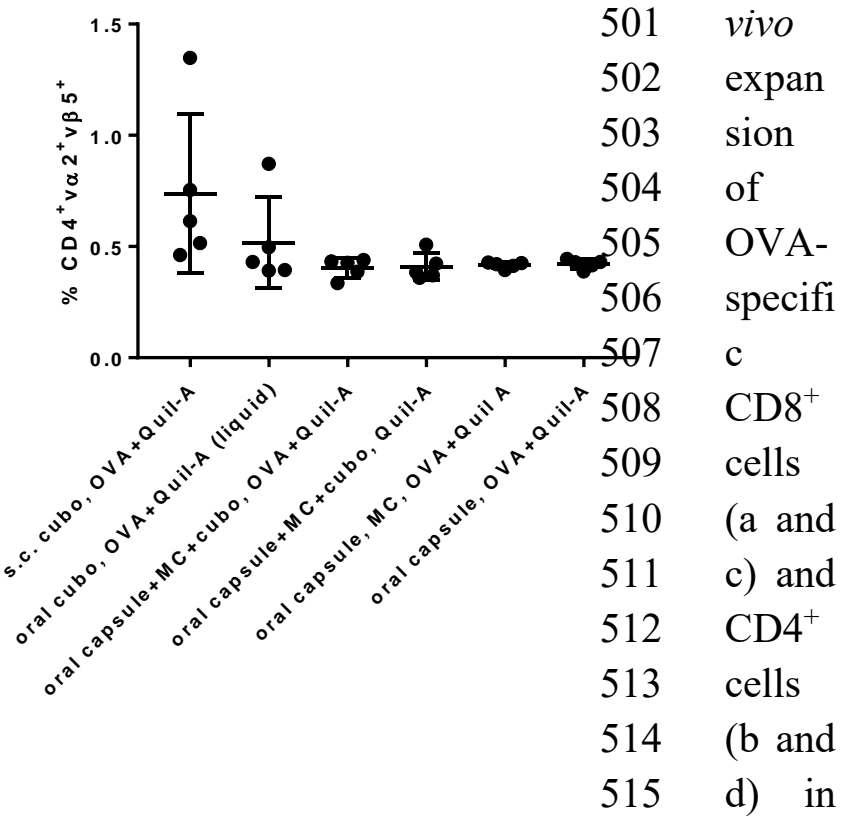

516 lymph nodes ( $a$ and $b$ ) and spleens ( $c$ and d). Mice were given vaccines three times orally or

517 two times s.c. as indicated, with 14 days between each vaccination. Data shown are results

518 from individual mice together with the mean and SD from one of two independent 519 experiments $(\mathrm{n}=4-5$ mice $) .{ }^{*} \mathrm{p}<0.05$, cubo $=$ cubosomes, $\mathrm{MC}=$ microcontainers. 


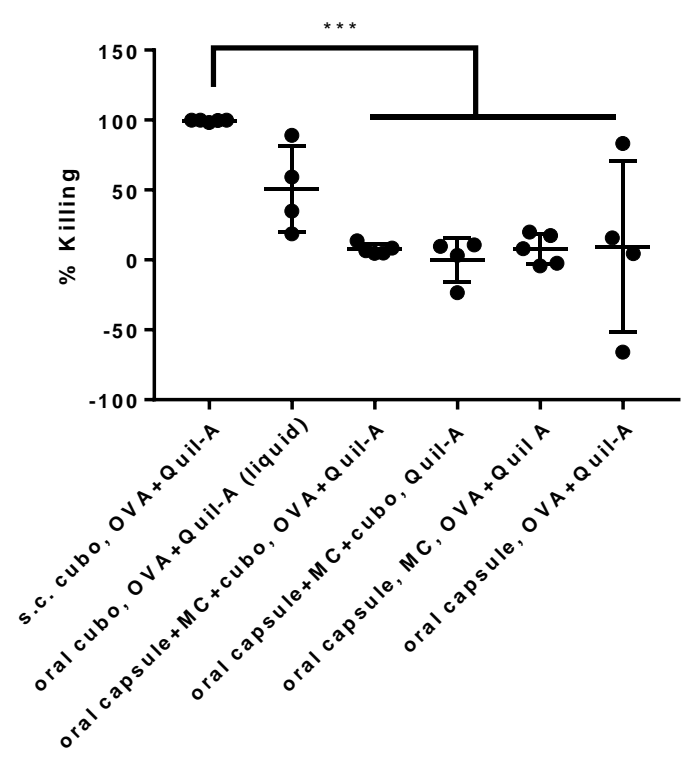

522 Figure 9. In vivo killing of adoptively transferred OVA-peptide labelled T cells in spleens.

523 Mice were given vaccines three times orally or two times s.c. as indicated with 14 days

524 between each vaccination. Data shown are results from individual mice together with mean 525 and SD from one of two independent experiments $(\mathrm{n}=4-5$ mice/experiment $) . * * * \mathrm{p}<0.001$, 526 cubo $=$ cubosomes, $\mathrm{MC}=$ microcontainers.

\subsection{Oral cubosomes in microcontainers have some effect as booster vaccine}

529 Doherty et al. reported that after an s.c. injected prime, an oral boost could stimulate a similar

530 level of protective immunity as a s.c. boost, although the oral vaccine was unable to prime an 531 immune response [49]. We therefore investigated if microcontainers with cubosomes with 532 OVA and Quil-A could stimulate an immune response when used as oral boost after an s.c. 533 injected prime of cubosomes.

534 Mice were given s.c. primes followed by two oral boosts (or s.c. boosts for the positive 535 control). In this experiment, the oral dose was reduced ten times to be the same as the s.c. 536 dose $(10 \mu \mathrm{g}$ OVA and $0.67 \mu \mathrm{g}$ Quil-A). OVA-specific serum IgG titers stimulated by s.c. 537 cubosomes was stronger than all oral groups $(\mathrm{p}<0.001$, Figure 10). Nonetheless, oral 538 boosters of cubosomes in microcontainers gave a slightly better antibody response than oral 539 boosters of cubosomes without microcontainers, indicating that the microcontainers help 540 deliver cubosomes orally as a booster vaccine (not significant, Figure 10). However, this 541 effect was not seen in the cellular response where $\mathrm{CD} 8^{+}$expansion after oral treatment with 542 cubosomes in microcontainers was similar to the $\mathrm{CD} 8^{+}$expansion after oral treatment with 543 cubosomes without microcontainers (Figure 11). The results could indicate that a parenteral 544 primer is necessary in later studies. 


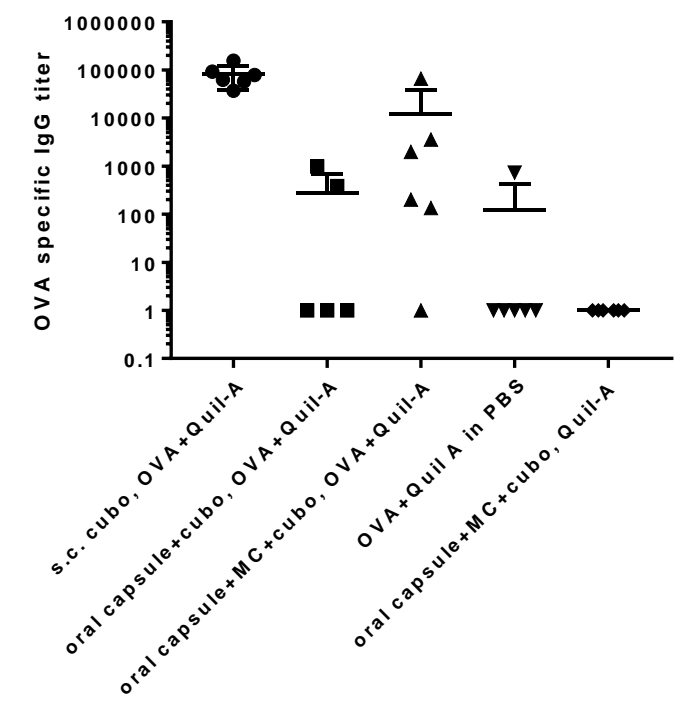

545

546 Figure 10. OVA-specific serum IgG antibody titers. Mice were given a priming dose of

547 vaccine by s.c. injection and then two s.c. or oral boosters as indicated. Vaccines were given

548 at 14 day intervals. In groups that received oral boosters with microcontainers, the s.c. prime

549 was injected without microcontainers. Data shown are from individual mice from a

550 representative experiment of three independent experiments together with mean and SD (n $=$ $5515-6$ mice/experiment). cubo $=$ cubosomes, $\mathrm{MC}=$ microcontainers.

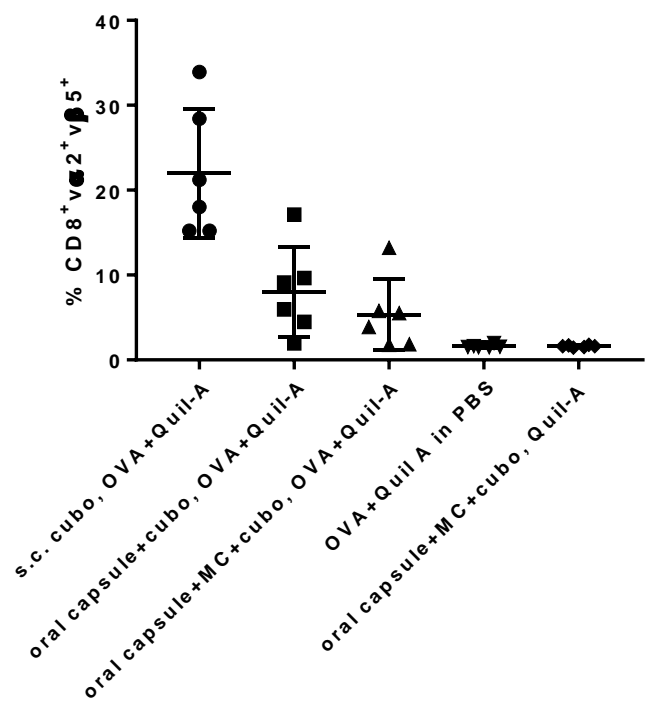

554 Figure 11. In vivo expansion of OVA-specific $\mathrm{CD} 8^{+}$cells in spleens. Mice were given a 555 priming dose of vaccine by s.c. injection and then two s.c. or oral boosters as indicated.

556 Vaccines were given at 14 day intervals. In groups that received oral boosters with

557 microcontainers, the s.c. prime was injected without microcontainers. Data shown are from

558 individual mice from a representative experiment of three independent experiments as well as 559 their average and SD ( $\mathrm{n}=5-6$ mice/experiment $)$. cubo = cubosomes, $\mathrm{MC}=$ microcontainers. 
562 Microcontainers hold great promise for protection of their cargo through the GI tract until

563 release in the mucus of the small intestine. The transit time of microcontainers through the

564 small intestine of mice is approximately 30-60 min. After release of the vaccine in the

565 intestine, these lids caused a change of the particle morphology from cubosomes to

566 hexosomes, which were stable for at least $21 \mathrm{~min}$ in intestinal fluid. However,

567 microcontainers were not successful in allowing oral delivery of a vaccine consisting of

568 cubosomes with OVA and Quil-A, but were able to slightly improve the humoral response to

569 oral boosters using the same vaccine at low doses. This work indicates that an oral delivery

570 system such as microcontainers should be focused on increasing the potency of vaccines that

571 have some immunogenicity after oral administration. This study further indicates that oral

572 vaccination is more easily achieved for booster vaccines after an injected primer.

573

\section{Acknowledgements}

575 This work was supported by the Danish National Research Foundation (DNRF122)

576 and Villum Fonden (Grant No. 9301) for Intelligent Drug Delivery and Sensing Using

577 Microcontainers and Nanomechanics (IDUN). Line Hagner Nielsen would like to thank the

578 Danish Research Council for Technology and Production (FTP), Project DFF 4004-00120B

579 for financial support.

580 The authors would like to thank Chiara Mazzoni for the profilometer measurements, Nanna

581 Bild for the graphical abstract graphics, Stephan Sylvest Keller for designing the new shadow

582 mask for the photolithography process, Jesper Yue Pan for producing the microcontainers

583 and Lasse Højlund Thamdrup for measuring the microcontainer dimensions. Jacob Rune

584 Jørgensen and Marcell Wolf are acknowledged for help with SAXS measurements and

585 Sophie Susanna Strindberg Andersen for help with $\mathrm{pH}$ measurement of mouse GI tract fluid.

586 The scattering experiments in this manuscript were performed at the Austrian SAXS/WAXS

587 beamline at the synchrotron light source ELETTRA (Trieste, Italy).

\section{Conflicts of interest}

590 The authors have no conflicts of interest to declare. 
593 [1] C. Foged, Subunit vaccines of the future: the need for safe, customized and optimized particulate delivery systems, Ther. Deliv. 2 (2011) 1057-1077. doi:10.4155/tde.11.68.

[2] WHO, Position Papers - Summary of WHO Position Papers-Recommendations for Routine Immunization, Immunization,Vaccines Biol. (2018). http://www.who.int/immunization/policy/Immunization_routine_table1.pdf?ua=1 (accessed June 27, 2018).

[3] L.R. Feldstein, S. Mariat, M. Gacic-Dobo, M.S. Diallo, L.M. Conklin, A.S. Wallace, Global Routine Vaccination Coverage, 2016, MMWR. Morb. Mortal. Wkly. Rep. 66 (2017) 1252-1255. doi:10.15585/mmwr.mm6645a3.

[4] J.E. Vela Ramirez, L.A. Sharpe, N.A. Peppas, Current state and challenges in developing oral vaccines, Adv. Drug Deliv. Rev. 114 (2017) 116-131. doi:10.1016/j.addr.2017.04.008.

[5] K.J. McHugh, R. Guarecuco, R. Langer, A. Jaklenec, Single-injection vaccines: Progress, challenges, and opportunities, J. Control. Release. 219 (2015) 596-609. doi:10.1016/j.jconrel.2015.07.029.

[6] E.J. Kunkel, E.C. Butcher, Plasma-cell homing, Nat. Rev. Immunol. 3 (2003) $822-$ 829. doi:10.1038/nri1203.

[7] B. Premanand, M. Prabakaran, T.K. Kiener, J. Kwang, Recombinant Baculovirus Associated with Bilosomes as an Oral Vaccine Candidate against HEV71 Infection in Mice, PLoS One. 8 (2013) e55536. doi:10.1371/journal.pone.0055536.

[8] J.R. McGhee, J. Mestecky, M.T. Dertzbaugh, J.H. Eldridge, M. Hirasawa, H. Kiyono, The mucosal immune system: from fundamental concepts to vaccine development, Vaccine. 10 (1992) 75-88. doi:10.1016/0264-410X(92)90021-B.

[9] Q. Zhu, J. Talton, G. Zhang, T. Cunningham, Z. Wang, R.C. Waters, J. Kirk, B. Eppler, D.M. Klinman, Y. Sui, S. Gagnon, I.M. Belyakov, R.J. Mumper, J.A. Berzofsky, Large intestine-targeted, nanoparticle-releasing oral vaccine to control genitorectal viral infection, Nat. Med. 18 (2012) 1291-1296. doi:10.1038/nm.2866.

[10] V. Pavot, N. Rochereau, C. Genin, B. Verrier, S. Paul, New insights in mucosal $\begin{array}{lllll}\text { vaccine development, } & \text { Vaccine. } & 30 & \text { (2012) }\end{array}$ doi:10.1016/j.vaccine.2011.11.003.

[11] J. Myschik, T. Rades, S. Hook, Advances in Lipid-Based Subunit Vaccine Formulations, Curr. Immunol. Rev. 5 (2009) 42-48. doi:10.2174/157339509787314378.

[12] Z. Abid, C. Gundlach, O. Durucan, C. von Halling Laier, L.H. Nielsen, A. Boisen, S.S. Keller, Powder embossing method for selective loading of polymeric microcontainers with drug formulation, Microelectron. Eng. 171 (2017) 20-24. doi:10.1016/j.mee.2017.01.018.

[13] L.H. Nielsen, A. Melero, S.S. Keller, J. Jacobsen, T. Garrigues, T. Rades, A. Müllertz, A. Boisen, Polymeric microcontainers improve oral bioavailability of furosemide., Int. J. Pharm. 504 (2016) 98-109. doi:10.1016/j.ijpharm.2016.03.050. 
[14] C. Mazzoni, F. Tentor, S.A. Strindberg, L.H. Nielsen, S.S. Keller, T.S. Alstrøm, C. Gundlach, A. Müllertz, P. Marizza, A. Boisen, From concept to in vivo testing: Microcontainers for oral drug delivery, J. Control. Release. 268 (2017) 343-351. doi:10.1016/j.jconrel.2017.10.013.

[15] P. Marizza, S.S. Keller, A. Müllertz, A. Boisen, Polymer-filled microcontainers for oral delivery loaded using supercritical impregnation, J. Control. Release. 173 (2014) 1-9. doi:10.1016/j.jconrel.2013.09.022.

[16] L. Hagner Nielsen, S.S. Keller, A. Boisen, Microfabricated devices for oral drug delivery, Lab Chip. 00 (2018) 1-11. doi:10.1039/c81c00408k.

[17] L.H. Nielsen, T. Rades, B. Boyd, A. Boisen, Microcontainers as an oral delivery system for spray dried cubosomes containing ovalbumin, Eur. J. Pharm. Biopharm. 118 (2017) 13-20. doi:10.1016/j.ejpb.2016.12.008.

[18] A. Ahmed, C. Bonner, T.A. Desai, Bioadhesive microdevices with multiple reservoirs: a new platform for oral drug delivery, J. Control. Release. 81 (2002) 291-306. doi:10.1016/S0168-3659(02)00074-3.

[19] H.D. Chirra, L. Shao, N. Ciaccio, C.B. Fox, J.M. Wade, A. Ma, T.A. Desai, Planar Microdevices for Enhanced In Vivo Retention and Oral Bioavailability of Poorly Permeable Drugs, Adv. Healthc. Mater. 3 (2014) 1648-1654. doi:10.1002/adhm.201300676.

[20] E.L. McConnell, A.W. Basit, S. Murdan, Measurements of rat and mouse gastrointestinal $\mathrm{pH}$, fluid and lymphoid tissue, and implications for in-vivo experiments, J. Pharm. Pharmacol. 60 (2008) 63-70. doi:10.1211/jpp.60.1.0008.

[21] C.D. Garner, D.A. Antonopoulos, B. Wagner, G.E. Duhamel, I. Keresztes, D.A. Ross, V.B. Young, C. Altier, Perturbation of the Small Intestine Microbial Ecology by Streptomycin Alters Pathology in a Salmonella enterica Serovar Typhimurium Murine Model of Infection, Infect. Immun. 77 (2009) 2691-2702. doi:10.1128/IAI.01570-08.

[22] S. Fierro, R. Seishima, O. Nagano, H. Saya, Y. Einaga, In vivo pH monitoring using boron doped diamond microelectrode and silver needles: Application to stomach disorder diagnosis, Sci. Rep. 3 (2013) 3257. doi:10.1038/srep03257.

[23] K.D. Kohl, A. Stengel, M. Samuni-Blank, M.D. Dearing, Effects of Anatomy and Diet on Gastrointestinal pH in Rodents, J. Exp. Zool. Part A Ecol. Genet. Physiol. 319 (2013) 225-229. doi:10.1002/jez.1786.

[24] A. Sjölander, J.C. Cox, Uptake and adjuvant activity of orally delivered saponin and ISCOM(TM) vaccines, Adv. Drug Deliv. Rev. 34 (1998) 321-338. doi:10.1016/S0169-409X(98)00046-5.

[25] R.S. Martín, R. Briones, Industrial uses and sustainable supply of Quillaja saponaria (Rosaceae) saponins, Econ. Bot. 53 (1999) 302-311. doi:10.1007/BF02866642.

[26] C. von Halling Laier, B. Gibson, M. van de Weert, B.J. Boyd, T. Rades, A. Boisen, S. Hook, L. Hagner Nielsen, Spray dried cubosomes with ovalbumin and Quil-A as a nanoparticulate dry powder vaccine formulation, Int. J. Pharm. (2018). doi:10.1016/J.IJPHARM.2018.08.036. 
[27] S.B. Rizwan, W.T. McBurney, K. Young, T. Hanley, B.J. Boyd, T. Rades, S. Hook, Cubosomes containing the adjuvants imiquimod and monophosphoryl lipid A stimulate robust cellular and humoral immune responses., J. Control. Release. 165 (2013) 16-21. doi:10.1016/j.jconrel.2012.10.020.

[28] B. Malik, R.K. Gupta, G. Rath, A.K. Goyal, Development of pH responsive novel emulsion adjuvant for oral immunization and in vivo evaluation, Eur. J. Pharm. Biopharm. 87 (2014) 589-597. doi:10.1016/j.ejpb.2014.03.014.

[29] K.J. Maloy, A.M. Donachie, A.M. Mowat, Induction of Th1 and Th2 CD4+ T cell responses by oral or parenteral immunization with ISCOMS, Eur. J. Immunol. 25 (1995) 2835-2841. doi:10.1002/eji.1830251019.

[30] A.M. Mowat, K.J. Maloy, A.M. Donachie, Immune-stimulating complexes as adjuvants for inducing local and systemic immunity after oral immunization with $\begin{array}{lllll}\text { protein antigens., } & \text { Immunology. } & 80 & \text { (1993) }\end{array}$ http://findit.dtu.dk/en/catalog/2270422292 (accessed June 28, 2018).

[31] A.M. Mowat, A.M. Donachie, G. Reid, O. Jarrett, Immune-stimulating complexes containing Quil A and protein antigen prime class I MHC-restricted T lymphocytes in vivo and are immunogenic by the oral route., Immunology. 72 (1991) 317-22. http://www.pubmedcentral.nih.gov/articlerender.fcgi?artid=1384389\&tool=pmcentrez \&rendertype $=$ abstract (accessed June 28, 2018).

[32] A. McI Mowat, R.E. Smith, A.M. Donachie, E. Furrie, D. Grdic, N. Lycke, Oral vaccination with immune stimulating complexes, in: Immunol. Lett., 1999: pp. 133140. doi:10.1016/S0165-2478(98)00136-9.

[33] S.A. Mohamedi, A.W. Heath, R. Jennings, A comparison of oral and parenteral routes for therapeutic vaccination with HSV-2 ISCOMs in mice; cytokine profiles, antibody responses and protection, Antiviral Res. 49 (2001) 83-99. doi:10.1016/S01663542(00)00142-X.

[34] M. Kazanji, F. Laurent, P. Péry, Immune responses and protective effect in mice vaccinated orally with surface sporozoite protein of Eimeria falciformis in ISCOMs, Vaccine. 12 (1994) 798-804. doi:10.1016/0264-410X(94)90288-7.

[35] K. Scheepers, H. Becht, Protection of mice against an influenza virus infection by oral vaccination with viral nucleoprotein incorporated into immunostimulating complexes, Med. Microbiol. Immunol. 183 (1994) 265-278. doi:10.1007/BF00198460.

[36] L.H. Nielsen, S.S. Keller, K.C. Gordon, A. Boisen, T. Rades, A. Müllertz, Spatial confinement can lead to increased stability of amorphous indomethacin, Eur. J. Pharm. Biopharm. 81 (2012) 418-425. doi:10.1016/j.ejpb.2012.03.017.

[37] T. Kojarunchitt, S. Baldursdottir, Y. Da Dong, B.J. Boyd, T. Rades, S. Hook, Modified thermoresponsive Poloxamer 407 and chitosan sol-gels as potential sustained-release vaccine delivery systems, Eur. J. Pharm. Biopharm. 89 (2015) 74-81. doi:10.1016/j.ejpb.2014.11.026.

[38] J. Myschik, W.T. Mcburney, T. Hennessy, A. Phipps-Green, T. Rades, S. Hook, Immunostimulatory biodegradable implants containing the adjuvant Quil-A-Part II: In vivo evaluation, J. Drug Target. $16 \quad$ (2008) 224-232. 
[39] M. Vertzoni, J. Dressman, J. Butler, J. Hempenstall, C. Reppas, Simulation of fasting gastric conditions and its importance for the in vivo dissolution of lipophilic compounds, Eur. J. Pharm. Biopharm. $60 \quad$ (2005) 413-417. doi:10.1016/j.ejpb.2005.03.002.

[40] S.T. Hyde, Identification of lyotropic liquid crystal mesophases, in: K. Holmberg (Ed.), Handb. Appl. Surf. Colloid Chem., 1st ed., John Wiley \& Sons, Ltd., New York, 2001: pp. 299-332. http://au.wiley.com/WileyCDA/WileyTitle/productCd0471490830.html (accessed October 15, 2017).

725

726

727

728

729

730

731

732

733

734

735

736

737

738

739

740

741

742

743

744

745

746

747

748

749

750

751

752

[41] G. Wörle, B. Siekmann, M.H.J. Koch, H. Bunjes, Transformation of vesicular into cubic nanoparticles by autoclaving of aqueous monoolein/poloxamer dispersions, Eur. J. Pharm. Sci. 27 (2006) 44-53. doi:10.1016/J.EJPS.2005.08.004.

[42] J.C. Shah, Y. Sadhale, D.M. Chilukuri, Cubic phase gels as drug delivery systems, Adv. Drug Deliv. Rev. 47 (2001) 229-250. doi:10.1016/S0169-409X(01)00108-9.

[43] M. Nakano, T. Teshigawara, A. Sugita, W. Leesajakul, A. Taniguchi, T. Kamo, H. Matsuoka, T. Handa, Dispersions of Liquid Crystalline Phases of the Monoolein/ Oleic Acid/Pluronic F127 System, (2002). doi:10.1021/la026297r.

[44] R. Rajabalaya, S.R.N. David, J. Khanam, A. Nanda, Studies on the effect of plasticizer on in vitro release and ex vivo permeation from Eudragit E 100 based chlorpheniramine maleate matrix type transdermal delivery system., J. Excipients Food Chem. 1 (2010) 3-12.

[45] T. Kaasgaard, C.J. Drummond, Ordered 2-D and 3-D nanostructured amphiphile selfassembly materials stable in excess solvent, Phys. Chem. Chem. Phys. 8 (2006) 49574975. doi:10.1039/b609510k.

[46] B.J. Boyd, Y.-D. Dong, T. Rades, Nonlamellar liquid crystalline nanostructured particles: advances in materials and structure determination., J. Liposome Res. 19 (2009) 12-28. doi:10.1080/08982100802691983.

[47] T. Storni, T.M. Kündig, G. Senti, P. Johansen, Immunity in response to particulate antigen-delivery systems., Adv. Drug Deliv. Rev. 57 (2005) 333-55. doi:10.1016/j.addr.2004.09.008.

[48] S. Phan, W.-K. Fong, N. Kirby, T. Hanley, B.J. Boyd, Evaluating the link between self-assembled mesophase structure and drug release, Int. J. Pharm. 421 (2011) 176182. doi:10.1016/j.ijpharm.2011.09.022.

[49] T.M. Doherty, A.W. Olsen, L. Van Pinxteren, P. Andersen, Oral vaccination with subunit vaccines protects animals against aerosol infection with Mycobacterium tuberculosis, Infect. Immun. 70 (2002) 3111-3121. doi:10.1128/IAI.70.6.31113121.2002 . 
Table S1: Vaccinations in study 1, where microcontainers were tested as an oral vaccine system.

\begin{tabular}{llll}
\hline Group no. & Vaccine formulation? & Dosage form & $\begin{array}{l}\text { Administrated } \\
\text { on days }\end{array}$ \\
\hline 1 & $\begin{array}{l}\text { Microcontainers + cubosomes }+ \\
\text { OVA + Quil-A }\end{array}$ & Oral capsule & 0,14 and 28 \\
2 & Microcontainers + OVA + Quil-A & Oral capsule & 0,14 and 28 \\
3 & Cubosomes + OVA + Quil-A & In $100 \mu \mathrm{L}$ PBS orally & 0,14 and 28 \\
4 & OVA + Quil-A & Oral capsule & 0,14 and 28 \\
5 & Microcontainers + cubosomes + & Oral capsule & 0,14 and 28 \\
6 & Quil-A & & 14 and 28
\end{tabular}

759

760

761 Table S2: Vaccinations in study 2 where microcontainers were tested as an oral booster 762 vaccine system.

\begin{tabular}{|c|c|c|}
\hline Group no. & Primer (day 0) & Booster (day 14 and 28) \\
\hline 1 & $\begin{array}{l}\text { Cubosome }+ \text { OVA }+ \text { Quil-A in } 200 \\
\mu \text { L PBS s.c. }\end{array}$ & $\begin{array}{l}\text { Microcontainers }+ \text { cubosomes }+ \text { OVA } \\
+ \text { Quil-A in oral capsule }\end{array}$ \\
\hline 2 & $\begin{array}{l}\text { Cubosome }+ \text { OVA }+ \text { Quil-A in } 200 \\
\mu \text { L PBS s.c. }\end{array}$ & $\begin{array}{l}\text { Cubosomes + OVA }+ \text { Quil-A orally in } \\
100 \mu \mathrm{L} \text { PBS }\end{array}$ \\
\hline 3 & OVA + Quil-A in $200 \mu \mathrm{L}$ PBS s.c. & OVA + Quil-A orally in $100 \mu \mathrm{L}$ PBS \\
\hline 4 & $\begin{array}{l}\text { Cubosome }+ \text { Quil-A in } 200 \mu \mathrm{L} \text { PBS } \\
\text { s.c. }\end{array}$ & $\begin{array}{l}\text { Microcontainers }+ \text { cubosomes }+ \text { Quil- } \\
\text { A in oral capsule }\end{array}$ \\
\hline 5 & $\begin{array}{l}\text { Cubosome }+ \text { OVA }+ \text { Quil-A in } 200 \\
\mu \text { L PBS s.c. }\end{array}$ & $\begin{array}{l}\text { Cubosome }+ \text { OVA }+ \text { Quil-A in } 200 \mu \mathrm{L} \\
\text { PBS s.c. }\end{array}$ \\
\hline
\end{tabular}


a)

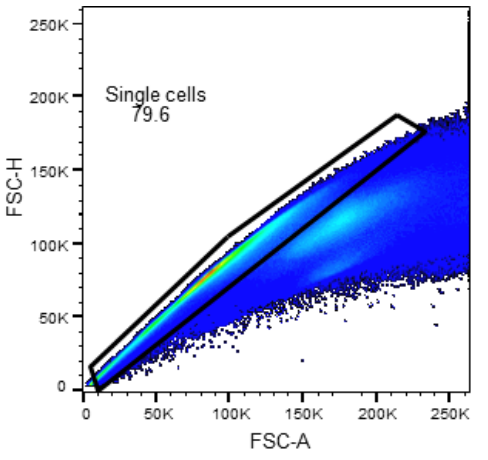

c)

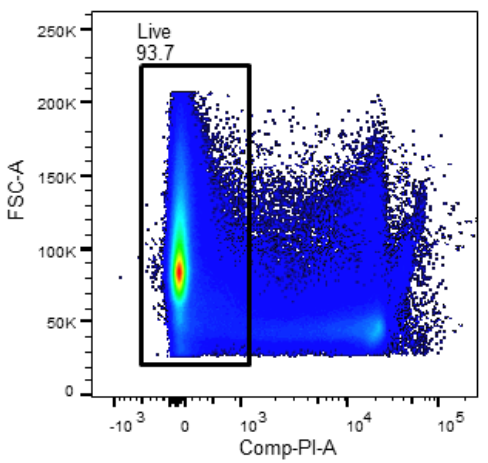

e)

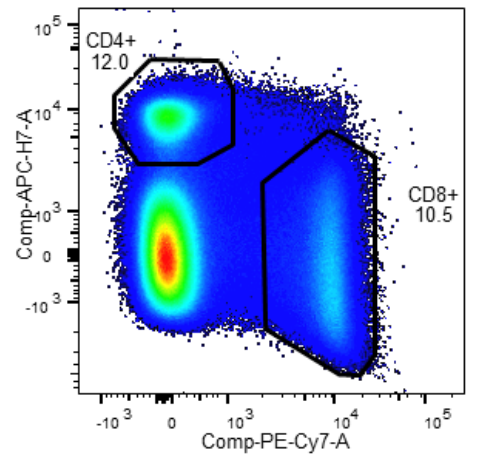

g)

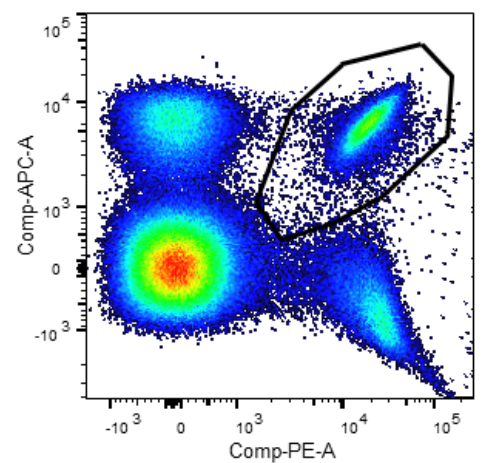

b)

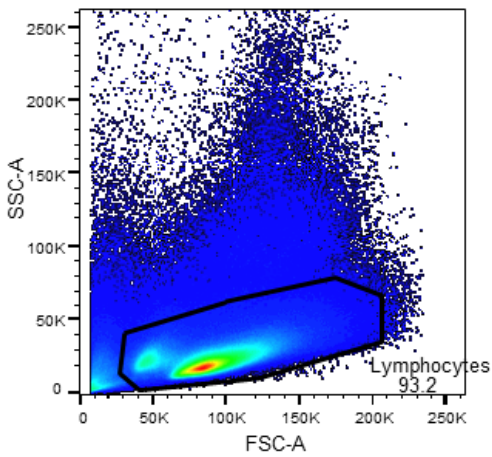

d)

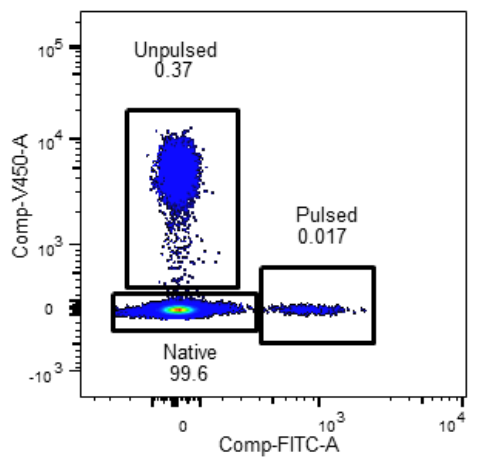

f)

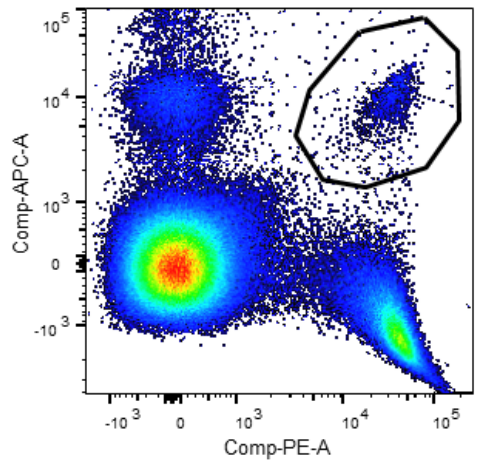

Figure S1. Gating setup for FACS analysis of OVA-peptide labelled target cells and transgenic OVA-specific $\mathrm{CD} 4^{+}$and $\mathrm{CD}^{+}$expansion. The example shown is from splenocytes from a mouse receiving oral PBS with cubosomes with OVA and Quil-A. Single cells were selected (a), followed by selecting lymphocytes (b), and excluding dead cells (c). OVApeptide pulsed and un-pulsed target cells were selected for the in vivo cytotoxic $\mathrm{T}$ cell killing assay and native cells selected for the OVA-specific T cell expansion assay (d). Gates were then set to select native cells expressing $\mathrm{CD}^{+}$and $\mathrm{CD} 8^{+}$receptors (e), and then transgenic $\mathrm{v}_{\alpha} 2^{+}$and $\mathrm{v}_{\beta} 5^{+}$receptors on $\mathrm{CD} 4^{+}$cells (f), and CD8 ${ }^{+}$cells (g). 
pH of the GI-tract of mice

\section{$775 \quad$ Methods}

776 Mice were sacrificed and their stomach and small intestine collected. The small intestine was divided into two segments (proximal and distal) of equal length. Segment fluid from four mice were pooled to allow complete submersion of a $\mathrm{pH}$-microelectrode (Metrohm, Herisau, Switzerland) connected to a SensION $+\mathrm{pH} 31 \mathrm{pH}$ meter $\left(\mathrm{HACH}^{\circledR}\right)$. Immediately after collecting the gastric and intestinal fluids, $\mathrm{pH}$ measurements were performed at $37^{\circ} \mathrm{C}$ on five independent samples.

\section{$782 \quad \underline{\text { Results }}$}

The $\mathrm{pH}$ of the fluid from the stomach and the proximal- and distal half of the small intestine was measured immediately after sacrificing the mice. The average $\mathrm{pH}$ in the stomach was 4.4 and the highest individual $\mathrm{pH}$-value recorded in the stomach was 4.7 (Figure $\mathrm{S} 2$ ). The average $\mathrm{pH}$ of the small intestine was 5.9 (proximal segment) and 6.6 (distal segment). The lowest individual $\mathrm{pH}$-value recorded in the intestine was 5.8 and the highest 7.1. These results showed that the $\mathrm{pH}$-sensitive polymer must be stable below $\mathrm{pH} 4.7$ and must dissolve at $\mathrm{pH}$-values above 5.8. EL100-55 was therefore chosen as it dissolves at $\mathrm{pH}$-values above 5.5 .

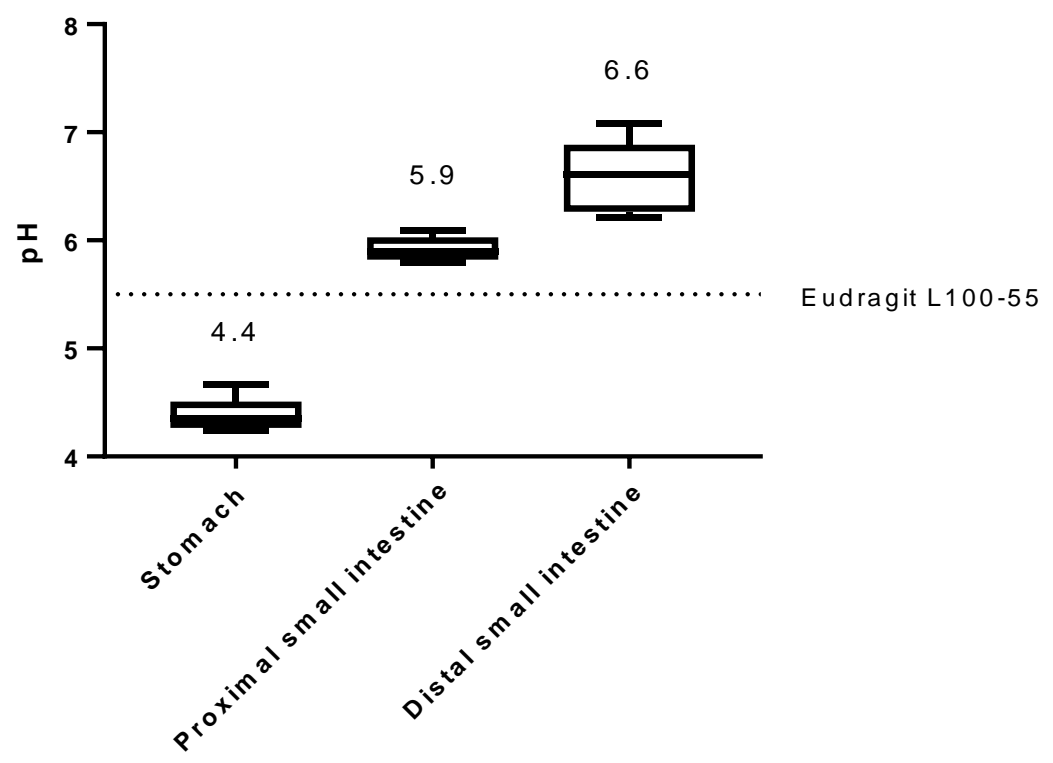

792 Figure S2. $\mathrm{pH}$ of fluids from the GI tract from mice measured at $37^{\circ} \mathrm{C}$ immediately after sacrifice. Whiskers on the boxplots indicate maximum and minimum $(n=5)$. Averages are written above each group, and $\mathrm{pH} 5.5$, above which EL100-55 begins to dissolve, is marked on the figure. 


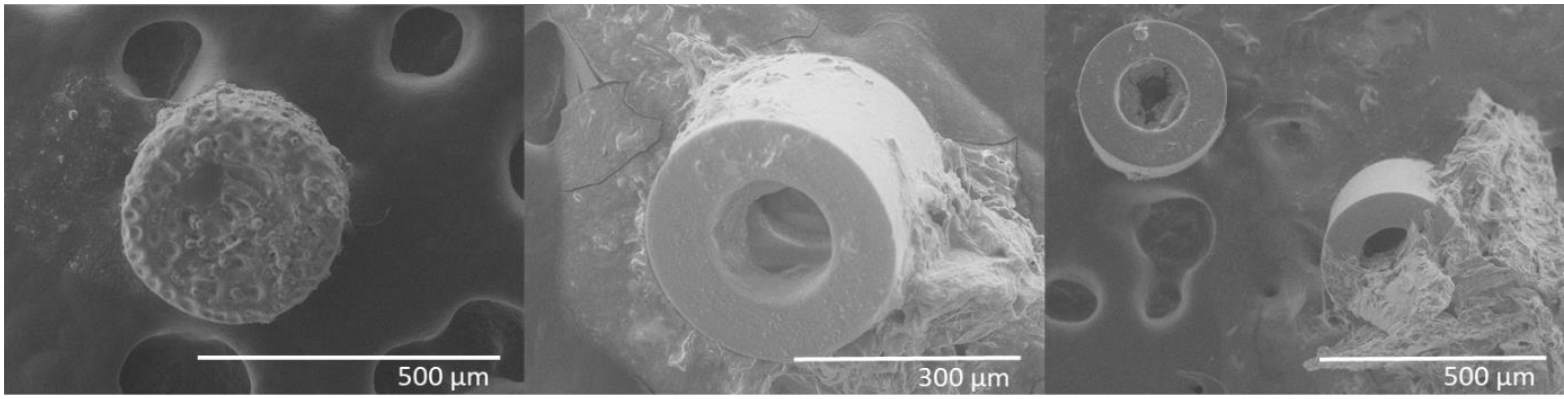

798 Figure S3. Representative SEM images of microcontainers after $30 \mathrm{~min}$ submersion into 799 fluid from the stomach (a), proximal segment of the small intestine (b), and distal segment of 800 the small intestine (c), in vitro at $37^{\circ} \mathrm{C}$ and rotation at $120 \mathrm{rpm}$.

801 